\title{
miR-146b-5p promotes the neural conversion of pluripotent stem cells by targeting Smad4
}

\author{
NIANPING ZHANG ${ }^{1 *}$, YING LYU $^{1 *}$, XUEBING PAN $^{2}$, LIPING XU $^{1}$, AIGUO XUAN $^{1}$, \\ XIAOSONG HE ${ }^{1}$, WANDAN HUANG ${ }^{1}$ and DAHONG LONG ${ }^{1}$ \\ ${ }^{1}$ Department of Human Anatomy, Guangzhou Medical University, Guangzhou, Guangdong 511436; \\ ${ }^{2}$ Department of Human Anatomy, College of Health Sciences of Guangzhou Medical University, \\ Guangzhou, Guangdong 510180, P.R. China
}

Received May 20, 2016; Accepted June 30, 2017

DOI: $10.3892 /$ ijmm.2017.3064

\begin{abstract}
Pluripotent stem cells (PSCs) are regarded as potential sources that provide specific neural cells for cell therapy in some nervous system diseases. However, the mechanisms underlying the neural differentiation of PSCs remain largely unknown. MicroRNAs (miRNAs or miRs) are a class of small non-protein-coding RNAs that act as critical regulatory molecules in many cellular processes. In this study, we found that miR-146b-5p expression was markedly increased following the neural induction of mouse embryonic stem cells (ESCs) or induced PSCs (iPSCs). In this study, to further identify the role of miR-146b-5p, we generated stable miR-146b-5poverexpressing ESC and iPSC cell lines, and induced the differentiation of these cells by the adherent monolayer culture method. In the miR-146b-5p-overexpressing ESC- or iPSCderived cultures, RT-qPCR analysis revealed that the mRNA expression levels of neuroectoderm markers, such as Sox1, Nestin and Pax6, were markedly increased, and flow cytometric analysis verified that the number of Nestin-positive cells was higher in the miR-146b-5p-overexpressing compared with the control cells. Mechanistically, the miR-146b-5p-overexpressing ESCs or iPSCs exhibited a significant reduction in Oct 4 expression, which may be an explanation for these cells having a tendency to differentiate towards the neural lineage. Moreover, we confirmed that miR-146b-5p directly targeted Smad4 and negatively regulated the transforming growth factor (TGF)- $\beta$ signaling pathway, which contributed to the neural commitment of PSCs. Collectively, our findings uncover the essential role of $\mathrm{miR}-146 \mathrm{~b}-5 \mathrm{p}$ in the neural conversion of PSCs.
\end{abstract}

Correspondence to: Professor Dahong Long, Department of Human Anatomy, Guangzhou Medical University, Panyu, Guangzhou, Guangdong 511436, P.R. China

E-mail: longdahong88@qq.com

${ }^{*}$ Contributed equally

Key words: pluripotent stem cells, neural commitment, transforming growth factor- $\beta$ signaling pathway, Smad 4 , microRNA

\section{Introduction}

Pluripotent stem cells (PSCs), including embryonic stem cells (ESCs) and induced PSCs (iPSCs), are self-renewing cells and are able to differentiate into cell types from all three germ layers (1). Therefore, they provide potential sources for cell replacement therapy in neurodegenerative diseases and spinal cord injuries (2). The high-yield production of homogenous neuronal cell subtypes is necessary for cell therapy. However, the derivatives of PSCs may contain proliferating non-neural cells and undifferentiated cells by using current neural induction protocols, which is unacceptable for cell transplantation due to the risk of tumor formation (3-6). Although a number of molecular signatures that are involved in neurogenesis have been identified, the precise molecular mechanisms underlying the neural differentiation of PSCs remain to be elucidated.

The transforming growth factor- $\beta$ (TGF- $\beta$ ) signaling pathway plays an important role in a variety of cellular processes, including cell growth, migration, proliferation and differentiation, as well as cell survival and apoptosis $(7,8)$. The vertebrate TGF- $\beta$ superfamily can be divided into two subfamilies: the TGF- $\beta$ /Activin/Nodal subfamily and the bone morphogenetic protein (BMP)/growth differentiation factor (GDF)/Müllerian-inhibiting substance (MIS) subfamily $(9,10)$. The ligands of the TGF- $\beta$ superfamily bind to type I and II serine/threonine kinase receptors (11-13), resulting in the formation of ligand-receptor complexes in which type II receptors are activated (14). The type I receptors are then phosphorylated by activated type II receptors $(11,12,14)$. Subsequently, activated type I receptors phosphorylate and activate downstream receptor-regulated Smads (R-Smads), including Smad1, 2, 3, 5 and 8 (9,12-14). Phosphorylated R-Smads interact with common-mediator Smad4 (co-Smad4), forming oligomeric R-Smad/co-Smad complexes which translocate into the nucleus and regulate the transcription of specific genes (11-15). It has been reported that the dual inhibition of the two subfamilies of TGF- $\beta$ signaling pathways induce the efficient neuralization of PSCs (10).

MicroRNAs (miRNAs or miRs) are a class of small nonprotein-coding RNAs, approximately 21 to 23 nucleotides in length (16-18). The mature miRNA directly binds to the 
3' untranslational region (3'UTR) of a specific mRNA, leading to mRNA cleavage or translational repression (18-21). miRNAs act as critical regulatory molecules in various biological and pathologic processes, such as cell growth, self-renewal, proliferation, differentiation, apoptosis and stress resistance $(13,16,17,19,22)$. Accumulating evidence has emerged to indicate that miRNAs are involved in the regulation of TGF- $\beta$ signaling by targeting the TGF- $\beta$ superfamily receptors, Smads and other components of the TGF- $\beta$ signaling pathway (23). However, the mechanisms through which miRNAs coordinate with TGF- $\beta$ signaling pathway to influence PSC fate determination are not yet fully understood. miR-146b-5p, a highly conserved miRNA, was previously found to be significantly upregulated in neural stem cells (NSCs) that differentiated from rhesus monkey ESCs (24). Of note, it has been reported that $\mathrm{miR}-146 \mathrm{~b}-5 \mathrm{p}$ regulates TGF- $\beta$ signal transduction by repressing Smad4 in a rat thyroid follicular cell line (25).

In this study, we discovered that the expression level of miR-146b-5p was also markedly increased following the neural induction of mouse ESCs or iPSCs. Thus, stable miR-146b-5poverexpressing ESC and iPSC cell lines were generated to explore the role of miR-146b-5p in ESC or iPSC differentiation. We observed that miR-146b-5p-overexpressing ESCs or iPSCs exhibited a significant reduction in Oct4 expression. Importantly, we identified that miR-146b-5p negatively regulated the TGF- $\beta$ signaling pathway via the suppression of Smad4, which contributed to the commitment of mouse PSCs to the neural lineage.

\section{Materials and methods}

Cell culture. Mouse iPSCs expressing an Oct4-GFP fusion gene (OS402B-1; Guangzhou Institute of Biomedicine and Health, Chinese Academy of Sciences, Guangzhou, China) and mouse ESCs (R1) (ATCC, Manassas, VA, USA) were used in the present study. The two cell lines were cultured on mitomycin C-treated mouse embryonic fibroblasts (MEFs) in Dulbecco's modified Eagle's medium (DMEM) supplemented with $15 \%$ knockout serum replacement (KSR), $0.1 \mathrm{mM}$ nonessential amino acids (NEAAs) and $2 \mathrm{mM}$ L-glutamine (all from Gibco Life Technologies, Grand Island, NY, USA), $0.1 \mathrm{mM}$ 2-mercaptoethanol, $100 \mathrm{U} / \mathrm{ml}$ penicillin, $100 \mu \mathrm{g} / \mathrm{ml}$ streptomycin and 1,000 U/ml mouse leukemia inhibitory factor (LIF) (all from PeproTech Inc., Rocky Hill, NJ, USA). The culture medium was changed every day. The cells were dissociated into single cells by $0.25 \%$ trypsin and $0.53 \mathrm{mM}$ EDTA (Beijing Solarbio Science and Technology Co., Ltd., Beijing, China) and passaged on MEFs every 2-3 days.

Stable cell line generation. To generate stable miR-146b-5poverexpressing cell lines, we cloned miR-146b-5p pre-miRNA sequence with an additional $100 \mathrm{nt}$ flanking each end by using polymerase chain reaction (PCR) amplification with mouse genomic DNA as templates. For the generation of Smad4overexpressing cell lines, we cloned the cDNA of Smad4 from the total RNA of R1 ESCs (all primers are listed in Table I). After the PCR products were inserted into pSin-EF1 $\alpha$-IRES-prou vectors, the constructs containing the miR-146b-5p premiRNA sequence or Smad4 sequence were confirmed by DNA sequencing. To produce lentiviral particles, pSin-miR-146b-5p or pSin-Smad4 vectors were co-transfected with package vectors, including pSPAX2 and pMD2.G into 293T cells. 293T cells were obtained from the cell bank of the Chinese Academy of Sciences (Shanghai, China). The medium was refreshed the following day, and the viral supernatant was harvested after 2 days. The ESCs or iPSCs were transfected with lentiviruses, and then cultured in selection media containing $2 \mu \mathrm{g} / \mathrm{ml}$ puromycin for 2-3 days. The control cells were untransfected cells.

Neural induction. The mouse ESCs or iPSCs were induced to differentiate into NSCs using the adherent monolayer culture method as previously reported with some modifications (26). Briefly, the ESCs and iPSCs were passaged at least once on gelatin-coated dishes in the presence of LIF $(2,000 \mathrm{U} / \mathrm{ml})$ in medium prior to differentiation, in order to eliminate contaminating MEFs (27). Undifferentiated cells were dissociated and seeded out on gelatinized tissue culture plastics at a density of $0.5-1.5 \times 10^{4} / \mathrm{cm}^{2}$ in ESC medium. After $24 \mathrm{~h}$, the medium was replaced with $\mathrm{N} 2 \mathrm{~B} 27$ medium consisting of a 1:1 mixture of DMEM/F12 supplemented with $1 \%$ N2 and Neurobasal medium supplemented with 2\% B27 (all from Gibco Life Technologies). After 9 days of culture, the cells were processed to immunocytochemistry and flow cytometry.

Reverse transcription-quantitative PCR (RT-qPCR) analysis. TotalRNA was isolated using TRIzol reagent (Life Technologies, Carlsbad, CA, USA). RNA was subjected to reverse transcription reactions to generate complementary DNA using the cDNA synthesis kit (Takara Bio Inc., Shiga, Japan) according to the manufacturer's instructions. Following reverse transcription, RT-qPCR was carried out with PrimeScript ${ }^{\mathrm{TM}}$ RT Reagent kit (Takara Bio Inc.) on an Applied Biosystems 7500/7500 Fast Real-Time PCR system (Applied Biosystems, Foster City, CA, USA). $\beta$-actin, a housekeeping gene, was used as the endogenous control. For miRNA RT-qPCR, miR-146b-5p was reverse transcribed using the specific stem-loop primer and cDNA synthesis kit (Takara Bio Inc.). The small nuclear RNA, U6, was used as a reference control. All the specific primer pairs used to analyze the target genes are listed in Tables II and III.

Immunocytochemistry. Immunocytochemical procedures were performed using previously described protocol with some modifications (28). The cultured cells were fixed with freshly prepared 4\% paraformaldehyde (PFA) for $15 \mathrm{~min}$ at room temperature, and treated with $0.3 \%(\mathrm{v} / \mathrm{v})$ Triton X-100 in $10 \%(\mathrm{w} / \mathrm{v})$ bovine serum albumin (BSA) for $40 \mathrm{~min}$. The cells were sequentially incubated overnight at $4^{\circ} \mathrm{C}$ with primary antibodies diluted in phosphate-buffered saline (PBS) plus $1 \%$ BSA. The cells were washed 3 times with PBS, followed by incubation for $2 \mathrm{~h}$ with appropriate secondary antibodies. Following 3 washes with PBS, the cultures were incubated with 4',6-diamidino2-phenylindole (DAPI) for $15 \mathrm{~min}$ to counterstain nuclei. The cells were then rinsed with PBS 3 times prior to visualization. The following primary antibodies were used: Oct4 (1:200; sc-5279; Santa Cruz Biotechnology, Inc., Santa Cruz, CA, USA), Nanog (1:500; NB100-58842; Novus Biologicals Inc., Littleton, CO, USA) and Nestin (1:100; ab6142; Abcam, Cambridge, UK).

Alkaline phosphatase (AP) staining. The medium was aspirated from the wells, and the wells were rinsed twice with PBS. The cells were fixed with $4 \%$ PFA at room tempera- 
Table I. Primers used for the generation of pre-miRNA or Smad4 sequences.

\begin{tabular}{lll}
\hline PCR products & \multicolumn{1}{c}{ Forward primer $\left(5^{\prime} \rightarrow 3^{\prime}\right)$} & \multicolumn{1}{c}{ Reverse primer $\left(5^{\prime} \rightarrow 3^{\prime}\right)$} \\
\hline miR-146b-5p pre-miRNA & ATCGGCGATCGCAACAGCCCAC & ATCGGTTTAAACAAGGTTCAGC \\
sequences & AGAAGAGAGCTCTG & TAAGGAGCCCCC \\
Smad4 sequences & CGGAATTCCCAGGTCATCCTGCT & CCATCGATTCAGTCTAAAGGCT \\
& CACCAGATG & GTGGGTCCGC \\
\hline
\end{tabular}

Table II. Primers used for the reverse transcription reaction.

\begin{tabular}{ll}
\hline Genes & \multicolumn{1}{c}{ Primer $\left(5^{\prime} \rightarrow 3^{\prime}\right)$} \\
\hline miR-146b-5p & CTCAACTGGTGTCGTGGAGTCGGCAA \\
TTCAGTTGAGAGCCTATG
\end{tabular}

ture for $2 \mathrm{~min}$. The cells were then equilibrated with AP buffer (10 mM Tris-HCl pH 9.5, $\left.100 \mathrm{mM} \mathrm{NaCl}, 50 \mathrm{mM} \mathrm{MgCl}{ }_{2}\right)$ for $5 \mathrm{~min}$ at room temperatue after twice washes with PBS containing 1\% Tween-20 (PBST). The AP buffer was removed and staining solution (0.9 mg nitroblue tetrazolium (NBT) and $0.7 \mathrm{mg}$ 5-Bromo-4-chloro-3-indolyl phosphate (BCIP) per $1 \mathrm{ml}$ of AP buffer) was added to the wells. Following incubation with staining solution at room temperature for $15 \mathrm{~min}$ (protected from light), the cells were washed twice with PBS. The cells were then observed under a CKX53 microscope (serial no. 6F40625; Olympus, Tokyo, JAPAN).

Flow cytometry (FACS). Following 9 days of differentiation in vitro, the cultures were trypsinized into single cells and washed once with FACS buffer [PBS plus $1 \%$ fetal bovine serum (FBS)]. The cells were fixed in Cytofix ${ }^{\mathrm{TM}}$ Fixation Buffer (BD Biosciences, Franklin Lakes, NJ, USA) for $15 \mathrm{~min}$ at room temperature. Following 3 washes with FACS buffer, permeabilization was performed using Phosflow ${ }^{\mathrm{TM}}$ Perm/Wash Buffer I (BD Biosciences) for $10 \mathrm{~min}$ at $4^{\circ} \mathrm{C}$. The cells were then incubated with primary antibody against Nestin (1:200; N5413; Sigma-Aldrich, St. Louis, MO, USA) diluted in Phosflow $^{\mathrm{TM}}$ Perm/Wash Buffer I for $15 \mathrm{~min}$ at $37^{\circ} \mathrm{C}$. The cells were washed with FACS buffer 3 times, followed by incubation with secondary antibody (1:500; A11008; Life Technologies, Eugene, OR, USA) in FACS buffer for $15 \mathrm{~min}$ at $37^{\circ} \mathrm{C}$. The cells were washed and resuspended in PBS. Analyses were performed using an Accuri C6 flow cytometer (BD Biosciences) and FlowJo software.

Prediction of target gene. For the prediction of the target gene, we used the TargetScan database (http://www.targetscan.org/ mmu_71/). For our selection, we used mouse species and searched for the Smad4 gene. This was followed by the entry of a microRNA name, such as miR-146b-5p.

Luciferase reporter assay. To verify whether the Smad4 gene is a direct target of miR-146b-5p, the putative miR-146b-5p target site in the Smad4 3'UTR or mutated 3'UTR of Smad4 gene was respectively cloned into the psiCHECK-2 vector downstream of the gene encoding the Renilla luciferase (RL). 293 T cells were transiently transfected with wild-type or mutant Smad4 3'UTR psiCHECK-2 plasmids and miR-146b-5p or control vectors (miR-146b-5p empty vectors) using Lipofectamine 2000 (Invitrogen Life Technologies, Carlsbad, CA, USA). The luciferase activities were quantified using the Dual

Table III. Primers used for RT-qPCR.

\begin{tabular}{lll}
\hline Genes & \multicolumn{1}{c}{ Forward primer $\left(5^{\prime} \rightarrow 3^{\prime}\right)$} & Reverse primer $\left(5^{\prime} \rightarrow 3^{\prime}\right)$ \\
\hline miR-146b-5p & ACACTCCAGCTGGGTGAGAACTGAATTCCA & TGGTGTCGTGGAGTCGGCAATT \\
U6 & CTCGCTTCGGCAGCACA & AACGCTTCACGAATTTGCGT \\
Oct4 & TAGGTGAGCCGTCTTTCCAC & GCTTAGCCAGGTTCGAGGAT \\
Sox2 & GCGGAGTGGAAACTTTTGTCC & CGGGAAGCGTGTACTTATCCTT \\
Nanog & CTCAAGTCCTGAGGCTGACA & TGAAACCTGTCCTTGAGTGC \\
Rex 1 & CCCTCGACAGACTGACCCTAA & TCGGGGCTAATCTCACTTTCAT \\
Sox 1 & AGGCAGCTGGGTCTCAGAAG & GAAATCAAAGGCACGCTGTCT \\
Pax6 & CTGCAGGCCACTGAAAAGT & TTCCAGGATCTGAGCGATCT \\
Smad4 & ACACCTGTCTCCTCCTTCAC & GGTTGCATAGGCAGGTTGTTTG \\
Lefty 1 & AGGTGGCCTGATCTACACAAG & ACCCGCTCATAGTGATATGGATT \\
Lefty2 & CCAACCGCACTGCCCTTAT & CGCGAAACGAACCAACTTGT \\
$\beta$-actin & CAGCCAGAATTTTCGAGAGGT & CAGTGCGATTGGAGCCATC \\
\hline
\end{tabular}


Luciferase Assay kit (Promega, Madison, WI, USA) according to the manufacturer's instructions. The RL activities were normalized to the activities of firefly luciferase (FL).

Western blot analysis. The cultures were washed twice with PBS and incubated in cell lysis buffer (RIPA; Thermo Fisher Scientific, Inc., Waltham, MA, USA) on ice for $30 \mathrm{~min}$. All cell lysates were centrifuged at the speed of 12,000 rpm for $10 \mathrm{~min}$ at $4^{\circ} \mathrm{C}$. The concentration of proteins in the supernatant was measured using the Pierce BCA Protein Assay kit (Thermo Fisher Scientific, Inc.). Protein extracts were boiled and resolved by $10 \%$ polyacrylamide gel by electrophoresis, and further electroblotted onto polyvinylidene difluoride (PVDF) membranes. After blocking with 5\% BSA for $2 \mathrm{~h}$ at room temperature, the PVDF membranes were incubated overnight at $4^{\circ} \mathrm{C}$ with the following primary antibodies: $\beta$-actin $(1: 1,000$; \#4970; Cell Signaling Technology, Inc., Danvers, MA, USA), and Smad4 (1:5,000; ab40759; Abcam). The PVDF membranes were then washed with Tris-buffered saline containing 1\% Tween-20 (TBST) and probed with the secondary antibody conjugated to horseradish peroxidase (anti-rabbit $\mathrm{IgG}$; 1:1,000; \#7074s; Cell Signaling Technology, Inc.) for $2 \mathrm{~h}$ at room temperature. Following 3 washes with TBST, detection was performed using an enhanced chemiluminescence kit (Beyotime Institute of Biotechnology, Haimen, China) plus the Syngene Bio Imaging system (Syngene, Frederick, MD, USA).

Statistical analysis. All experiments were independently repeated at least 3 times, and statistical analysis was performed using SPSS 18.0 statistical software (SPSS Inc., Chicago, IL, USA). The data are expressed as the means \pm SD. Pairwise comparisons between groups were conducted using the Student's t-test. When P-values were $<0.05$, the results were considered as statistically significant.

\section{Results}

Successful generation of miR-146b-5p-overexpressing ESCs or iPSCs. ESCs can efficiently differentiate into NSCs using the adherent monolayer culture method $(26,29)$. This is a simple method with which to drive pluripotent cell differentiation as there is no need for multicellular aggregation or co-culture induction (29). In this study, neural induction was performed using the adherent monolayer culture method. Following the neural induction of mouse ESCs or iPSCs, the cultures exhibited a marked downregulation in the levels of pluripotency markers, including Oct4, Sox2, Nanog and Rex1, suggesting that the majority of PSCs exited from pluripotency and cellular differentiation occurred (Fig. 1A). Importantly, we observed that the expression level of miR-146b-5p was markedly increased in the ESC or iPSC-derived cultures (day 9, D9), and was approximately 2.5- or 2.6-fold higher than the ESCs or iPSCs before neural induction (day 0, D0; Fig. 1B). To further identify the role of miR-146b-5p in ESCs or iPSCs, we transfected a lentiviral vector (lenti-miR-146b-5p) into the ESCs and iPSCs to induce the overexpression of endogenous miR-146b-5p. Following selection by puromycin, the remaining ESC or iPSC colonies were selected and expanded individually. In the process of cell culture, we observed that the lenti-miR-146b-5ptransfected ESCs or iPSCs did not display any obvious morphological changes in the presence of LIF. The ESCs or iPSCs transfected with lenti-miR-146b-5p propagated rapidly and formed many colonies with smooth boundaries (Fig. 1C). As shown in Fig. 1D, the results of RT-qPCR revealed that the expression level of miR-146b-5p was markedly increased in the lenti-miR-146b-5p-transfected ESCs or iPSCs, and was approximately 16- or 5.7-fold higher than that in the control ESCs or iPSCs, respectively $(\mathrm{P}<0.001)$. These data suggested that we successfully generated two cell lines that constitutively expressed robust and mature miR-146b-5p.

The enforced expression of $m i R-146 b-5 p$ does not induce the rapid differentiation of ESCs or iPSCs. We then investigated whether the overexpression of miR-146b-5p in the ESCs or iPSCs affects cell pluripotency. We analyzed the mRNA expression levels of markers of pluripotency, such as Oct4, Sox2, Nanog and Rex1. Surprisingly, the results of RT-qPCR revealed that the expression level of Oct4, an important marker for pluripotency, was significantly decreased in the ESCs or iPSCs transfected with lenti-miR-146b-5p ( $\mathrm{P}<0.05)$. However, the mRNA expression levels of Sox 2, Nanog and Rex1 remained unaltered (Fig. 2A). Although the overexpression of miR-146b-5p in the ESCs or iPSCs seemed to affect the expression of Oct4, we found that these cells could be expanded for at least 5 passages in vitro and still displayed typical ESC or iPSC morphology. As illustrated in Fig. 2B, immunofluorescence staining revealed that the lenti-miR-146b-5p-transfected ESCs expressed the pluripotency markers, Oct4 and Nanog, and the lenti-miR-146b-5ptransfected iPSCs expressed Nanog as well. Green fluorescence was detected in the miR-146b-5p-overexpressing iPSCs using a fluorescence microscope, indicating that these cells continually expressed Oct4. Furthermore, the lenti-miR-146b-5p-transfected ESCs or iPSCs were positive for AP (Fig. 2C), a widely accepted marker of PSCs (30). The above-mentioned experimental results confirmed that the miR-146b-5p-overexpressing ESCs or iPSCs, with a reduction in Oct4 expression, still exhibited typical characteristics of PSCs, indicating that the overexpression of miR-146b-5p in mouse ESCs or iPSCs did not induce immediate differentiation.

Neural commitment is enhanced in miR-146b-5poverexpressing ESCs or iPSCs. To investigate in detail whether miR-146b-5p affects the neural differentiation of ESCs or iPSCs, we cultured miR-146b-5p-overexpressing ESCs or iPSCs and control cells in N2B27 medium. After 9 days of culture, the cells expanded toward all directions, and a large number of small, elongated cells appeared (Fig. 3A). Rosettelike structures, positive for Nestin by immunofluorescence staining, were observed in both lenti-miR-146b-5p transfected cells and control cells (Fig. 3B). As expected, the expression levels of pluripotency markers (Oct4, Sox2, Nanog and Rex1) were also strongly decreased in the cultures derived from miR-146b-5p-overexpressing ESCs or iPSCs (Fig. 3C). In order to further evaluate the successful differentiation of the miR-146b-5p-overexpressing ESCs or iPSCs into NSCs, we examined the mRNA expression levels of specific markers of the neuroectoderm, such as Sox1, Nestin and Pax6 in the differentiated cells. We confirmed that the overexpression of miR-146b-5p in the ESCs led to a marked increase in the mRNA expression levels of Sox1, Nestin and Pax6; these levels 

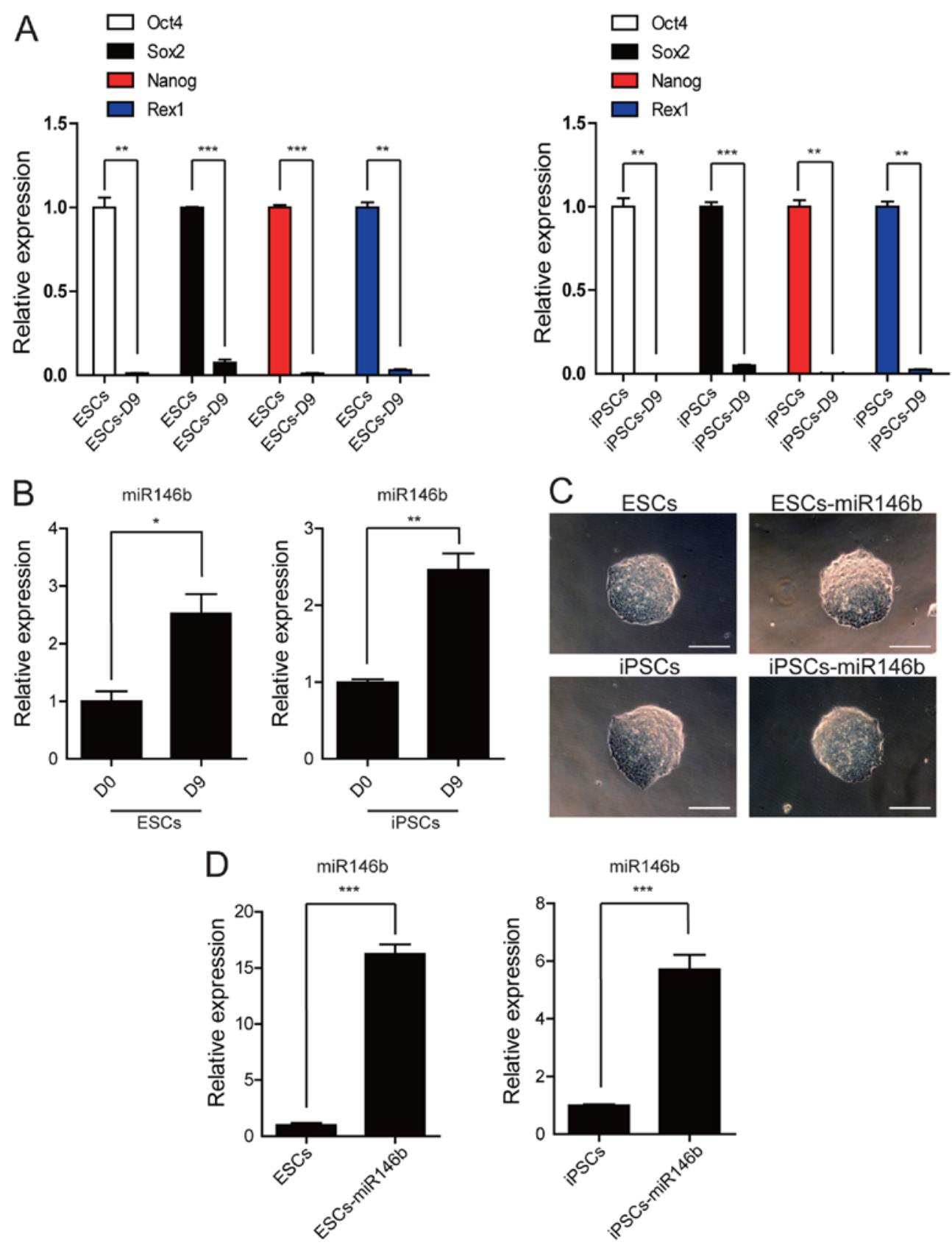

Figure 1. The generation of miR-146b-5p-overexpressing embryonic stem cells (ESCs) or induced pluripotent stem cells (iPSCs). (A) Following the neural induction of ESCs or iPSCs, the expression of pluripotency markers, including Oct4, Sox2, Nanog and Rex1, was significantly downregulated. (B) The expression level of miR-146b-5p was markedly increased in ESCs or iPSCs-derived cultures. (C) Clonal morphology of the control cells (including ESCs and iPSCs) and lenti-miR-146b-5p transfected ESCs or iPSCs. (D) Expression levels of miR-146b-5p were examined by RT-qPCR in control cells and lenti-miR-146b-5p-transfected ESCs or iPSCs. (C) Scale bar, $200 \mu \mathrm{m}$. (A, B and D) Data are expressed as the means $\pm \mathrm{SD},{ }^{*} \mathrm{P}<0.05 ;{ }^{* *} \mathrm{P}<0.01 ;{ }^{* * * *} \mathrm{P}<0.001$, as determined by the Student's t-test. D0, day 0 ; D9, day 9 following differentiation.

were approximately 2.9-, 1.8- and 2.7-fold higher than those in the ESC controls, respectively. Compared with the iPSC controls, the expression levels of Sox1, Nestin and Pax6 in the cultures derived from the lenti-miR-146b-5p-transfected iPSCs were significantly upregulated by 59.1, 85.3 and $24.1 \%$, respectively (Fig. 3D). Subsequently, flow cytometric analysis was performed to analyze the Nestin-positive cells. The results verified that the number of cells positive for Nestin in the lenti-miR-146b-5p-transfected ESCs or iPSCs was higher than that in the controls. As demonstrated in Fig. 3E, the number of Nestin-positive cells that differentiated from the miR-146b-5p-overexpressing ESCs or iPSCs was increased by an average of 5.4 and $9.2 \%$ compared with the control ESCs or iPSCs, respectively $(\mathrm{P}<0.05)$. Overall, these experimental data indicated that miR-146b-5p was capable of promoting the neural commitment of ESCs or iPSCs.

miR-146b-5p directly targets Smad4 and modulates TGF- $\beta$ signaling. To further elucidate the mechanisms through which miR-146b-5p executes its functions during ESC or iPSC neural differentiation, we used a miRNA-target prediction program, TargetScan, to screen for the candidate target genes of miR-146b-5p. We found that miR-146b-5p was predicted to target Smad4, a central transducer of both the TGF- $\beta$ and 
A

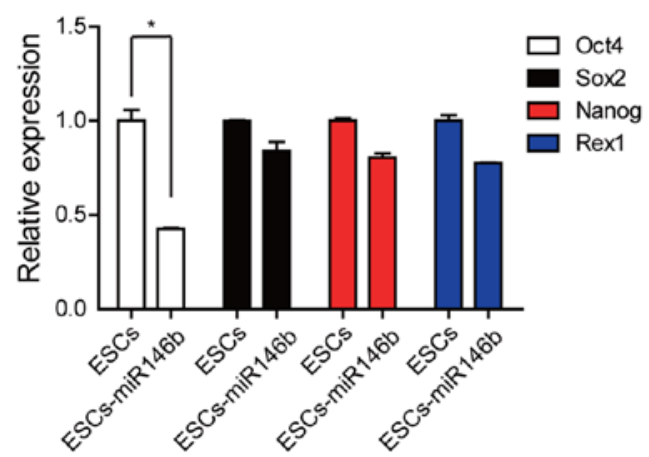

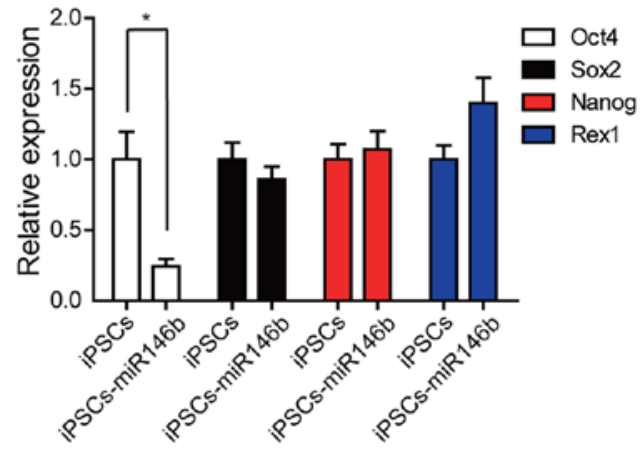

B

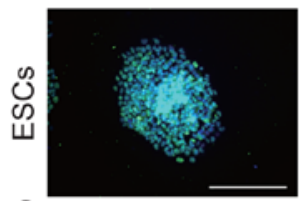

Nanog+DAPI
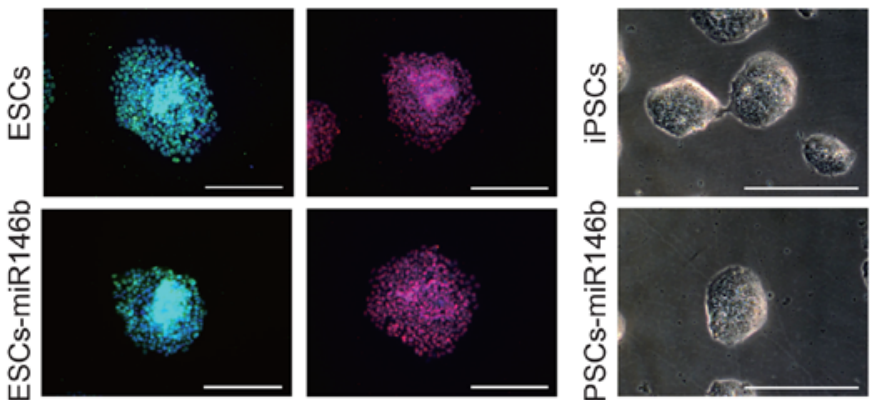

Oct4
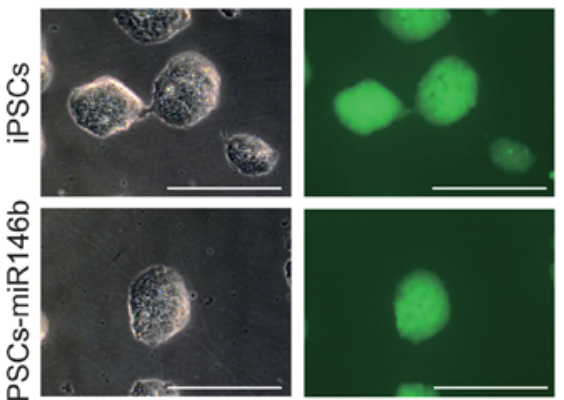

Nanog+DAPI
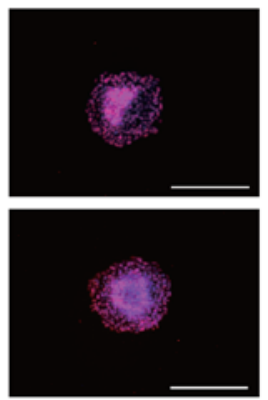
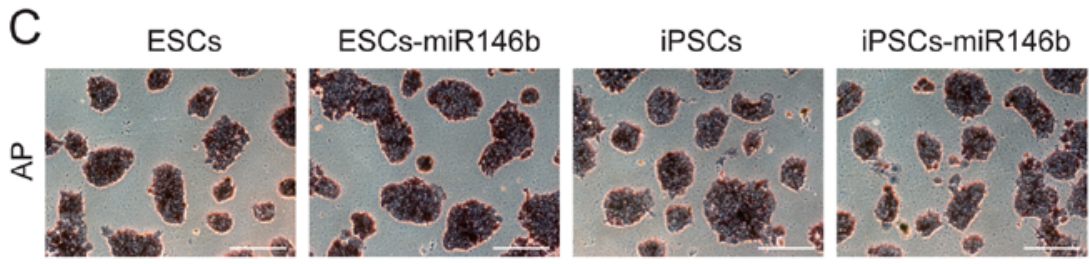

Figure 2. Overexpression of miR-146b-5p in embryonic stem cells (ESCs) or induced pluripotent stem cells (iPSCs) does not induce rapid differentiation. (A) Expression levels of four pluripotency markers (Oct4, Sox2, Nanog and Rex1) in control cells and miR-146b-5p-overexpressing ESCs or iPSCs. (B) Protein expression levels of Oct4 and Nanog were examined by immunostaining (green for Oct4, red for Nanog and blue for DAPI). Green fluorescence was detected in miR-146b-5p-overexpressing iPSCs using a fluorescence microscope. (C) Alkaline phosphatase (AP) staining of control cells and miR-146b-5p-overexpressing ESCs or iPSCs. (B and C) Scale bar, $200 \mu \mathrm{m}$. (A) Data are expressed as the mean $\pm \mathrm{SD},{ }^{*} \mathrm{P}<0.05$, as determined by the Student's t-test.

BMP signaling pathways (23). The mRNA of Smad4 had one potential complimentary binding site with miR-146b-5p within its 3'UTR (Fig. 4A). Hence, we evaluated the functional interaction of miR-146b-5p with the 3'UTR of Smad4 by a dual luciferase reporter assay. We constructed reporter vectors that contained the wild-type 3'UTR of Smad4, as well as the mutated miR-146b-5p target sequence (Fig. 4A). 293T cells were co-transfected with these reporter plasmids and miR-146b-5p or control vectors. Transfection of the reporter vectors containing the wild-type 3'UTR of Smad4 with miR-146b-5p vectors led to a significant decrease in relative luciferase activity compared with the control $(\mathrm{P}<0.001)$. However, the suppression of relative luciferase activity was not observed when the 3'UTR of Smad4 was mutated $(\mathrm{P}>0.05)$ (Fig. 4B). We then examined the expression levels of Smad4 in lenti-miR-146b-5p-transfected cells and control cells. As expected, RT-qPCR analysis revealed that the mRNA level of Smad4 in the lenti-miR-146b-5p-transfected ESCs or iPSCs was markedly reduced by 64.9 and $70.8 \%$ compared with the control ESCs or iPSCs, respectively (Fig.4C). The results of western blot analysis confirmed that the protein expression level of Smad4 was significantly decreased in the lenti-miR-146b-5p-transfected cells in comparison to the control cells (Fig. 4D). Smad4, also known as co-Smad, is a crucial partner in oligomeric Smad complexes. In the absence of Smad4, TGF- $\beta$ signaling is severely crippled (11). Based on the above, we then wished to determine whether the expression levels of downstream genes of TGF- $\beta$ signaling are suppressed by the decrease in Smad4 expression in the ESCs or iPSCs transfected with lenti-miR-146b-5p. We proceeded to detect the mRNA expression levels of TGF- $\beta$ signaling downstream genes, such as Leftyl and 2 (31-34). As shown in Fig. 4E, the expression levels of these genes were found to be significantly downregulated in the miR-146b-5p-overexpressing ESCs or iPSCs compared with the control ESCs or iPSCs, as shown by RT-qPCR analysis $(\mathrm{P}<0.001)$. These findings demonstrated that miR-146b-5p negatively regulated the TGF- $\beta$ signaling pathway by suppressing Smad4.

Neural differentiation is inhibited in Smad4-overexpressing ESCs or iPSCs. To determine whether Smad4 influences the neural commitment of ESCs or iPSCs, we transfected Smad4 lentiviral vectors (lenti-Smad4) into the ESCs and iPSCs to generate stable Smad4-overexpressing cell lines. As shown by the results of RT-qPCR analysis, the expression level of Smad4 was significantly increased in the lenti-Smad4-transfected ESCs or iPSCs, in comparison to the untransfected control cells (Fig. 5A); this was 


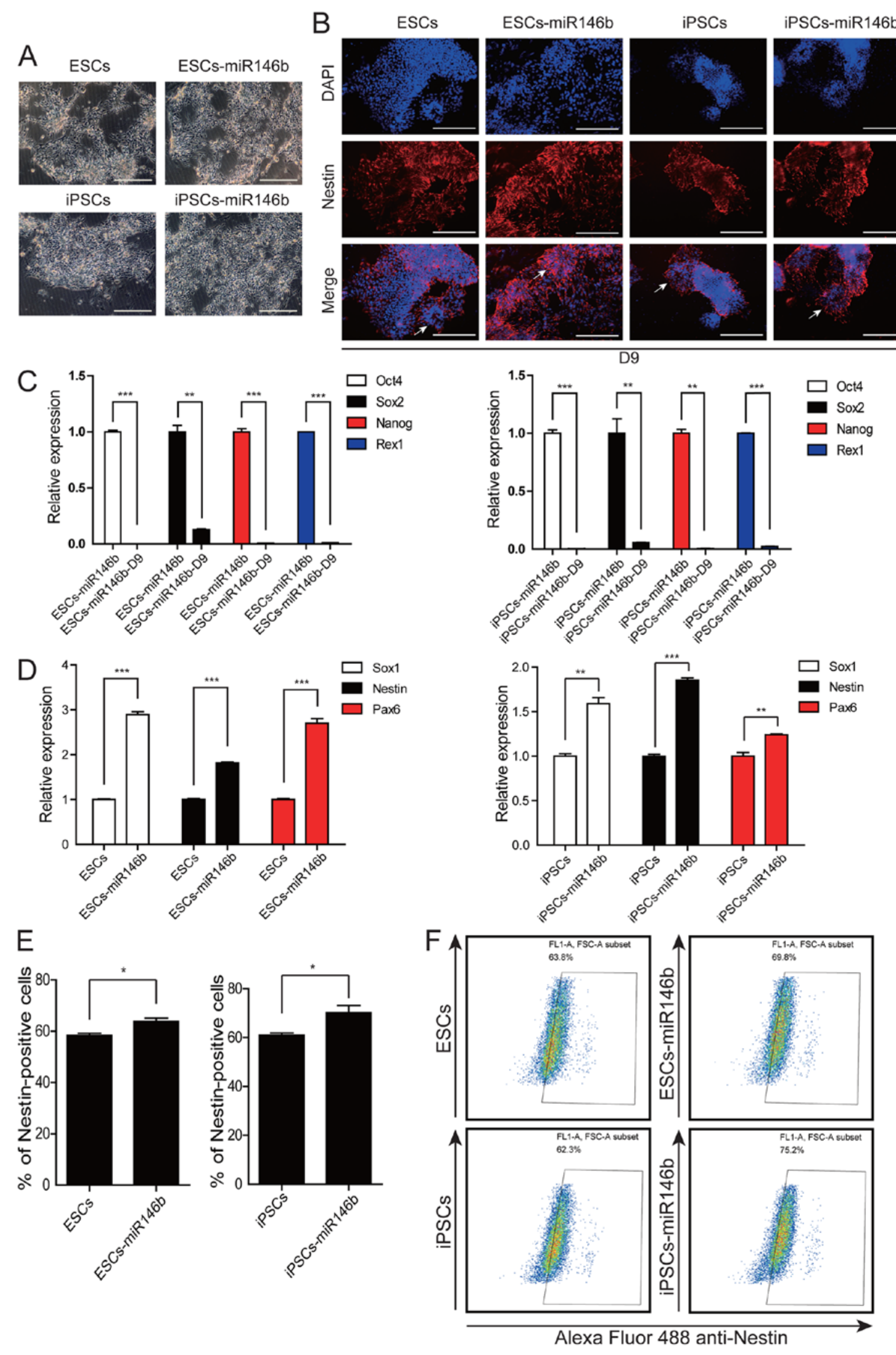

Figure 3. miR-146b-5p promotes the neural conversion of embryonic stem cells (ESCs) and induced pluripotent stem cells (iPSCs). (A) After 9 days of culture, large numbers of small elongated cells appeared. (B) Cultures were stained for neural stem cells (NSCs) with an antibody recognizing Nestin (red) and DAPI (blue) to stain the cell nuclei. Rosette-like structures (arrows) were observed in cultures derived from control cells and miR-146b-5p-overexpressing ESCs or iPSCs. (C) The expression of pluripotency markers was pronouncedly decreased in miR-146b-5p overexpressing ESCs or iPSCs-derived cultures. (D) Expression levels of neuroectoderm markers, including Sox1, Nestin and Pax6, were assessed by RT-qPCR. (E) The percentages of Nestin-positive cells for each cell line were plotted in the bar graphs. (F) Representative FACS profiles of Nestin-labeled population in derivatives of control cells and miR-146b-5p-overexpressing ESCs or iPSCs. (A and B) Scale bar, $200 \mu \mathrm{m}$. (C-E) Data are expressed as the means $\pm \mathrm{SD},{ }^{*} \mathrm{P}<0.05 ;{ }^{* * *} \mathrm{P}<0.01 ;{ }^{* * * *} \mathrm{P}<0.001$, as determined by the Student's t-test. 


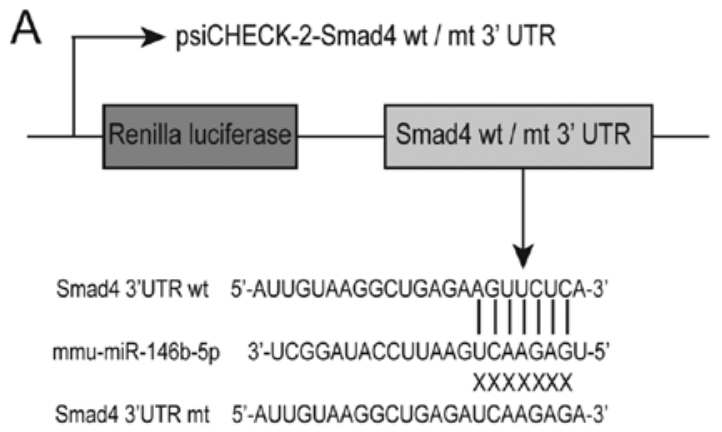

B Smad4 3' UTR wt

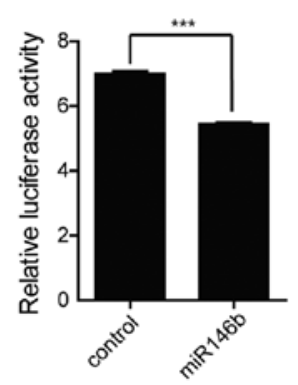

C
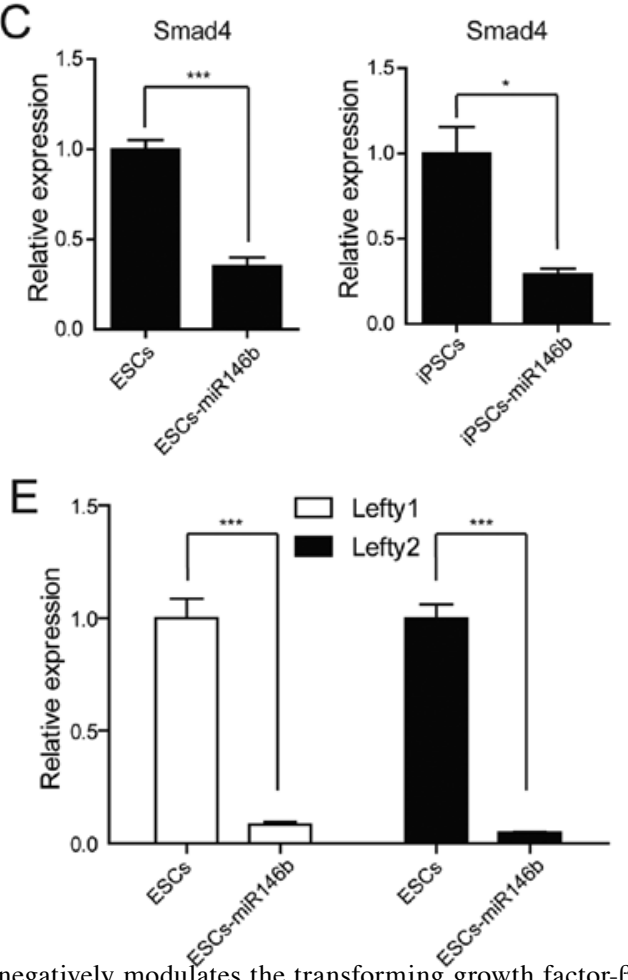

Figure 4. miR-146b-5p negatively modulates the transforming growth factor- $\beta$ (TGF- $\beta$ ) signaling pathway by directly targeting Smad4. (A) The putative miR-146b-5p binding sequences in the 3' untranslational region (3'UTR) of Smad4 mRNA was computationally predicted. The putative miR-146b-5p target site in the Smad4 3'UTR (wild-type, wt) and mutated 3'UTR of Smad4 gene (mutant-type, mt) were cloned into downstream of the luciferase gene separately. (B) Transfection of the reporter vectors containing wild-type 3'UTR of Smad4 with miR-146b-5p vectors led to a significant reduction in luciferase activity, whereas this reduction of luciferase activity was not observed when the 3'UTR of Smad4 was mutated. (C) The mRNA expression levels of Smad4 in control cells and miR-146b-5p-overexpressing embryonic stem cells (ESCs) or induced pluripotent stem cells (iPSCs) were determined by RT-qPCR. (D) Western blot analysis revealed a marked decrease in the protein expression levels of Smad4 in miR-146b-5p-overexpressing ESCs or iPSCs. (E) Expression levels of the TGF- $\beta$ signaling downstream genes, Lefty1 and 2 , were assessed by RT-qPCR. (B, C and E) Data are expressed as the means \pm SD, ${ }^{*} \mathrm{P}<0.05$; ${ }^{* * *} \mathrm{P}<0.001$, as determined by the Student's t-test.

further confirmed by western blot analysis (Fig. 5B). Following the neural induction of Smad4-overexpressing ESCs or iPSCs, typical rosette-like structures of neuroepithelial cells were also observed by immunofluorescence staining (Fig. 5C). However, RT-qPCR analysis revealed that the mRNA levels of neural markers (Sox1, Nestin and Pax6) were pronouncedly decreased in the cultures derived from Smad4-overexpressing ESCs or iPSCs, compared with the respective control cells (Fig. 5D). Moreover, FACS analysis revealed that the number of Nestin-positive cells differentiated from Smad4-overexpressing ESCs or iPSCs was reduced by an average of 17.9 and $14.3 \%$ in comparison to the control ESCs or iPSCs $(\mathrm{P}<0.05)$, respectively (Fig. 5E and F). Taken together, our findings indicated that the Smad4overexpressing ESCs or iPSCs exhibited a significant reduction in neural differentiation, indicating that Smad4 is an important regulator of neural cell fate decisions.

\section{Discussion}

TGF- $\beta$ signaling pathway and miRNAs both participate in various cellular processes. However, the association between the TGF- $\beta$ signaling pathway and miR-146b-5p in neurogenesis is not fully understood. In the present study, one of the main findings was that miR-146b-5p promotes the neural commitment of mouse PSCs, at least partially by blocking the expression of Smad4.

miRNAs are identified as important post-transcriptional regulators of embryonic development. To date, a number of miRNAs have been found to be involved in neurogenesis, including miR-376c, miR-134, miR-125 and miR-9a (33,35-37). miR-146b-5p, a highly conserved miRNA, shares the same nucleotide mature sequence in many species, such as Homo sapiens, Macaca mulatta and Mus musculus. miR-146b-5p has been 

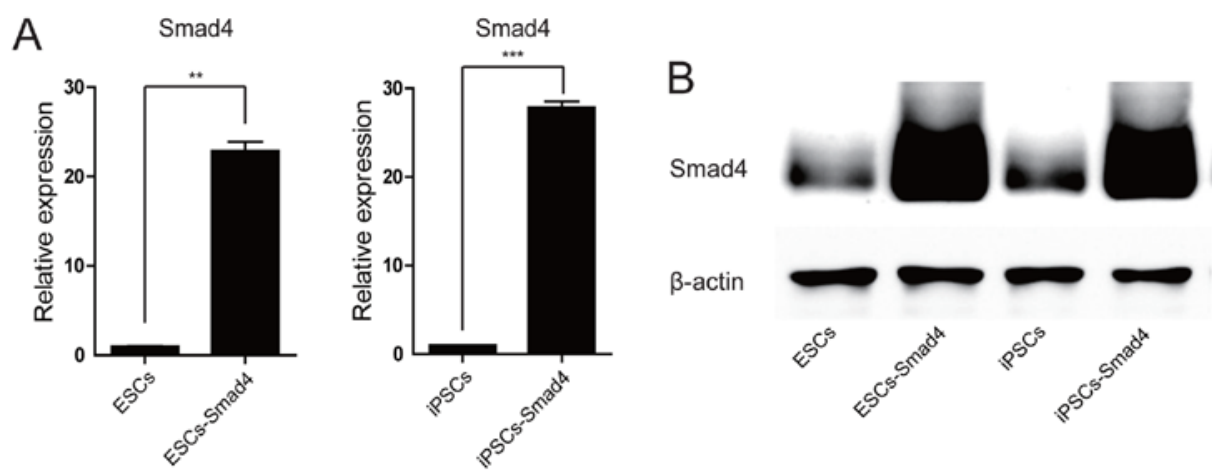

$\beta$-actin
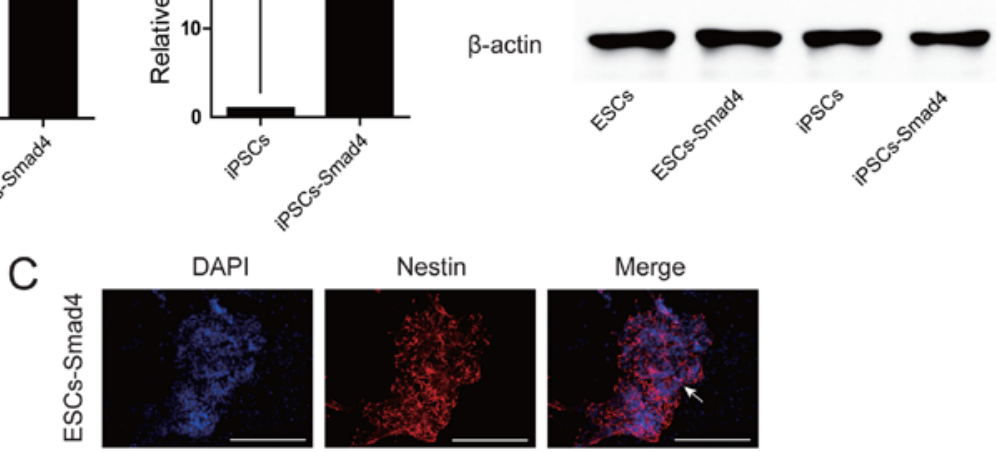

Nestin

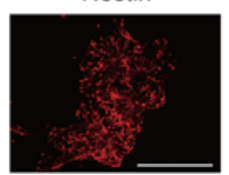

Merge
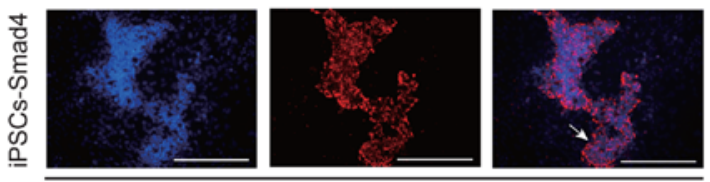

D9
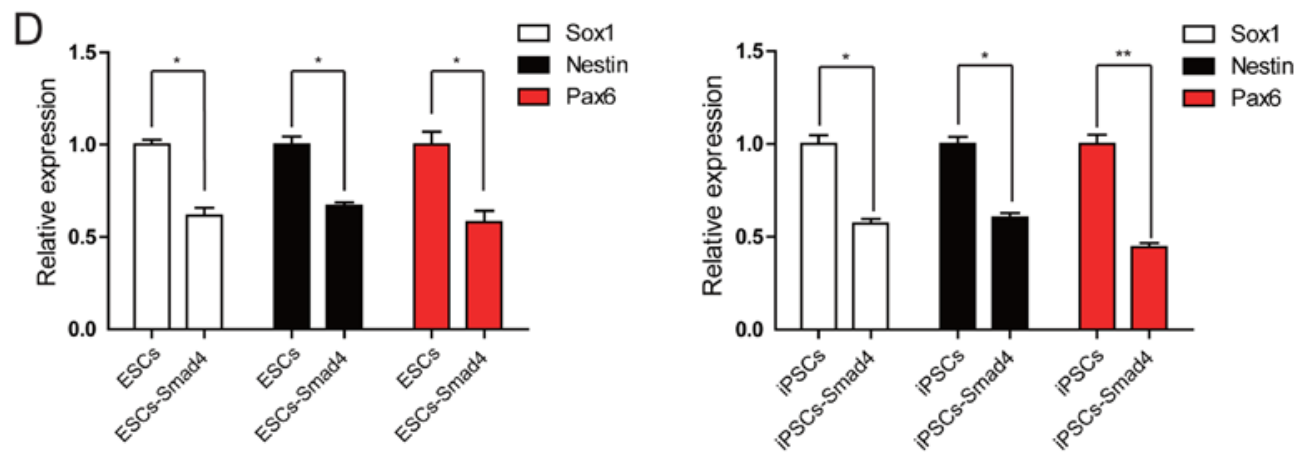

$E$
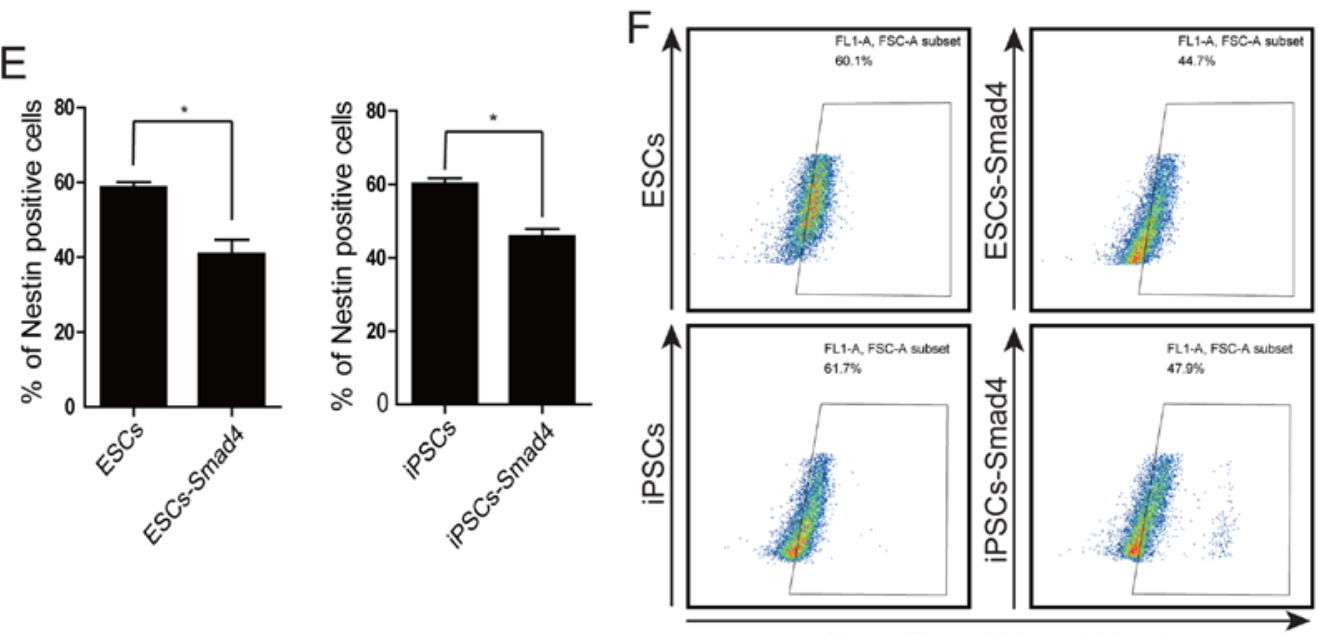

Alexa Fluor 488 anti-Nestin

Figure 5. Overexpression of Smad4 in embryonic stem cells (ESCs) or induced pluripotent stem cells (iPSCs) reduces neural differentiation. (A) The mRNA expression levels of Smad4 were markedly increased in lenti-Smad4-transfected ESCs or iPSCs. (B) Western blot analysis of Smad4 expression in control cells and lenti-Smad4-transfected ESCs or iPSCs. (C) Immunostaining of Nestin (red) and DAPI (blue) in differentiated cells (arrows indicate the location of rosette-like structures). (D) The mRNA levels of neuroectoderm markers (Sox1, Nestin and Pax6) were significantly reduced in Smad4-overexpressing ESCs or iPSCs-derived cultures. (E) The percentages of Nestin-positive cells for each cell line were plotted in the bar graphs. (F) Representative FACS profiles of the Nestin-labeled population in cultures derived from control cells and Smad4-overexpressing ESCs or iPSCs. (C) Scale bar, $200 \mu \mathrm{m}$. (A, D and E) Data are expressed as the means $\pm \mathrm{SD},{ }^{*} \mathrm{P}<0.05 ;{ }^{* * *} \mathrm{P}<0.01 ;{ }^{* * * *} \mathrm{P}<0.001$, as determined by the Student's t-test.

reported to be related to cancer growth (38), cell proliferation and migration (39). It was recently discovered that miR-146b-5p is significantly upregulated after rhesus monkey ESCs differentiate into NSCs (24). In the present study, the same observation 
was also found in mouse ESCs and iPSCs. We discovered that miR-146b-5p expression was markedly increased following the neural induction of mouse ESCs or iPSCs. Of note, miR-146b-5p was highly expressed in cultures derived from human NSCs by standard differentiation protocols. In addition, miR-146b-5p induces human NSCs to express $\beta$-tubulin III, a neuronal precursor marker (40). Based on these results, we hypothesized that miR-146b-5p was associated with the neural commitment of PSCs. Therefore, miR-146b-5p-overexpressing cell lines were generated to further elucidate the role of miR-146b-5p. According to the results of RT-qPCR and FACS analyses, we confirmed that neural conversion was pronouncedly enhanced in miR-146b-5p-overexpressing cells.

It has been reported that miR-146b-5p regulates the TGF- $\beta$ signaling pathway by repressing Smad4 in the rat thyroid follicular cell line, PCCL3 (25). However, it is not clear whether miR-146b-5p suppresses Smad4 and promotes neural differentiation in mouse PSCs. By using the miRNA-target prediction program, we found that miR-146b-5p was also predicted to target Smad4 in Mus musculus. Luciferase reporter assay revealed that the Smad4 was a direct target of miR-146b-5p in mouse ESCs and iPSCs. We observed that the expression of Smad4 in miR-146b-5p-overexpressing cells was markedly decreased at both the mRNA and protein level. Furthermore, the expression levels of downstream genes of TGF- $\beta$ signaling, Lefty1 and 2, were significantly downregulated in ESCs or iPSCs transfected with lenti-miR-146b-5p. These data suggest that miR-146b-5p negatively regulates the TGF- $\beta$ signaling pathway via the suppression of Smad4 in mouse PSCs. It is worth noting that TGF- $\beta$ superfamily members play a critical role in the control of PSC self-renewal and the maintenance of the pluripotent state $(8,10,41)$. A previously published study demonstrated that the inhibition of the Activin/Nodal signaling pathways by TGF- $\beta 1 /$ ALK inhibitor potentially suppressed the pluripotent gene, Oct4, in mouse ESCs (27). In the present study, the miR-146b-5p-overexpressing ESCs or iPSCs, with the downregulation of Smad4, exhibited a significant decrease in Oct4 mRNA expression. It is possible that the TGF- $\beta$ signaling pathway was blocked by the miR-146b-5p-mediated downregulation of Smad4, resulting in a reduction in Oct4 expression. Of note, Oct 4 has been reported to specifically suppress neural ectodermal differentiation. The neural ectodermal fate becomes available to ESCs when Oct4 is downregulated to a low level (42). Following the overexpression of miR-146b-5p in ESCs or iPSCs, we observed a reduction in Oct4 expression, which may provide an explanation for the miR-146b-5p-overexpressing ESCs or iPSCs having a tendency to differentiate toward the neural lineage.

The TGF- $\beta$ signaling pathway plays a pivotal role in the neural induction of the early embryo. As described by the 'default model', the conversion of embryonic cells to the neuronal fate requires the elimination of TGF- $\beta$ signaling, and this conversion is direct and does not require the concomitant induction of mesendodermal fates (43). A previous study have confirmed that the inhibition of the TGF- $\beta$ signaling pathway is sufficient to directly induce neural fate in not only mammalian embryos, but also human and mouse pluripotent embryonic stem cells (44). Smad4 is a crucial transducer of the TGF- $\beta$ signaling pathway (23). In vertebrates, Smad 4 can form oligomeric Smad complexes with R-Smads, which facili- tates their nuclear translocation, leading to the activation of target genes $(9,11)$. The TGF- $\beta$ signaling pathway is markedly blocked in the absence of Smad4 (11). It has previously been demonstrated that mouse ESCs with the deletion of Smad4 favor a neural fate in vitro (45). In comparison to wild-type mouse ESCs, Smad4 ${ }^{-/}$ESCs are more likely to differentiate into Nestin-positive cells (46). In our study, we observed that the downregulation of Smad4 by miR-146b-5p also resulted in an efficient conversion of PSCs into NSCs. The BMP signal, one branch of the TGF- $\beta$ signaling pathway, inhibits the neural differentiation of ESCs (47). Upon differentiation, ESCs in which Smad4 is knocked down are not able to respond to BMP4 and have a greater propensity to differentiate toward the neural lineage (36). Notably, Smad4 can directly bind and suppress Pax6, an important neural lineage specification factor (33). The targeted inhibition of Smad4 may be a solution to release Pax6 from Smad4-mediated suppression, which therefore may potentially direct PSCs to adopt neural fates. Our experimental data confirmed that the overexpression of Smad4 in ESCs or iPSCs led to a significant decrease in neural differentiation. By contrast, the miR-146b-5p-overexpressing ESCs or iPSCs, with the downregulation of Smad4, had a tendency to differentiate into the neural lineage. These results indicate that miR-146b-5p exerts a positive effect on the neural induction of PSCs by repressing Smad4 expression. Nevertheless, it is possible that miR-146b-5p plays other unknown roles to induce the neural differentiation of PSCs, which require further investigation.

In conclusion, our study reveals that miR-146b-5p-overexpressing ESCs or iPSCs exhibit a reduction in Oct4 expression, which may enable ESCs or iPSCs to have a propensity to differentiate into NSCs. Furthermore, we provide strong evidence that miR-146b-5p negatively regulates the signal transduction of TGF- $\beta$ by suppressing Smad4, and promotes the neural induction of PSCs. This study highlights the importance of post-transcriptional regulatory mechanisms that affect the neural differentiation of PSCs.

\section{Acknowledgements}

We would like to thank Dr Meng Zhang (Department of Physiology, Augusta University, Augusta, GA, USA) for critically reviewing of this study. This study was supported by the Natural Science Foundation of Guangdong Province (2016A030313584), Science and Technology Foundation of Guangzhou City (2014J4100065), the Science Foundation of Education Bureau of Guangzhou City (2012C042), and the Characteristic Innovation Foundation of Innovative and Strong University Project of Guangdong Province (Education and Science Missive of Guangdong Province 2014 65).

\section{References}

1. Fridley KM, Kinney MA and McDevitt TC: Hydrodynamic modulation of pluripotent stem cells. Stem Cell Res Ther 3: 45, 2012.

2. Lewandowski J and Kurpisz M: Techniques of human embryonic stem cell andinduced pluripotent stem cell derivation. Arch Immunol Ther Exp (Warsz) 64: 349-370, 2016.

3. Nefzger CM, Su CT, Fabb SA, Hartley BJ, Beh SJ, Zeng WR, Haynes JM and Pouton CW: Lmxla allows context-specific isolation of progenitors of GABAergic or dopaminergic neurons during neural differentiation of embryonic stem cells. Stem Cells 30: 1349-1361, 2012. 
4. Sonntag KC, Pruszak J, Yoshizaki T, van Arensbergen J, Sanchez-Pernaute R and Isacson O: Enhanced yield of neuroepithelial precursors and midbrain-like dopaminergic neurons from human embryonic stem cells using the bone morphogenic protein antagonist noggin. Stem Cells 25: 411-418, 2007.

5. Sundberg M, Bogetofte H, Lawson T, Jansson J, Smith G, Astradsson A, Moore M, Osborn T, Cooper O, Spealman R, et al Improved cell therapy protocols for Parkinson's disease based on differentiation efficiency and safety of hESC-, hiPSC-, and non-human primate iPSC-derived dopaminergic neurons. Stem Cells 31: 1548-1562, 2013.

6. Doi D, Morizane A, Kikuchi T, Onoe H, Hayashi T, Kawasaki T, Motono M, Sasai Y, Saiki H, Gomi M, et al: Prolonged maturation culture favors a reduction in the tumorigenicity and the dopaminergic function of human ESC-derived neural cells in a primate model of Parkinson's disease. Stem Cells 30 : 935-945, 2012.

7. Míguez DG, Gil-Guiñón E, Pons S and Martí E: Smad2 and Smad 3 cooperate and antagonize simultaneously in vertebrate neurogenesis. J Cell Sci 126: 5335-5343, 2013.

8. Seuntjens E, Umans L, Zwijsen A, Sampaolesi M, Verfaillie CM and Huylebroeck D: Transforming growth factor type $\beta$ and Smad family signaling in stem cell function. Cytokine Growth Factor Rev 20: 449-458, 2009.

9. Rodríguez-Martínez G and Velasco I: Activin and TGF- $\beta$ effects on brain development and neural stem cells. CNS Neurol Disord Drug Targets 11: 844-855, 2012.

10. Neely MD, Litt MJ, Tidball AM, Li GG, Aboud AA, Hopkins CR, Chamberlin R, Hong CC, Ess KC and Bowman AB: DMH1, a highly selective small molecule BMP inhibitor promotes neurogenesis of hiPSCs: comparison of PAX6 and SOX1 expression during neural induction. ACS Chem Neurosci 3: 482-491, 2012.

11. Heldin CH and Moustakas A: Role of Smads in TGF $\beta$ signaling. Cell Tissue Res 347: 21-36, 2012.

12. Miyazono K and Miyazawa K: Id: a target of BMP signaling. Sci STKE 2002: pe40, 2002

13. Yao G, Yin M, Lian J, Tian H, Liu L, Li X and Sun F: MicroRNA-224 is involved in transforming growth factor- $\beta$-mediated mouse granulosa cell proliferation and granulosa cell function by targeting Smad4. Mol Endocrinol 24: 540-551, 2010.

14. Tian T and Meng AM: Nodal signals pattern vertebrate embryos. Cell Mol Life Sci 63: 672-685, 2006.

15. Fortunel NO, Hatzfeld A and Hatzfeld JA: Transforming growth factor-beta: pleiotropic role in the regulation of hematopoiesis Blood 96: 2022-2036, 2000.

16. Hao J, Zhang S, Zhou Y, Liu C, Hu X and Shao C: MicroRNA 421 suppresses DPC4/Smad4 in pancreatic cancer. Biochem Biophys Res Commun 406: 552-557, 2011.

17. Hao J, Zhang S, Zhou Y, Hu X and Shao C: MicroRNA 483-3p suppresses the expression of DPC4/Smad4 in pancreatic cancer. FEBS Lett 585: 207-213, 2011.

18. Zhang J, Zhang Z, Zhang DY, Zhu J, Zhang T and Wang C: MicroRNA 126 inhibits the transition of endothelial progenitor cells to mesenchymal cells via the PIK3R2-PI3K/Akt signalling pathway. PLoS One 8: e83294, 2013.

19. Xia X, Zhang K, Cen G, Jiang T, Cao J, Huang K, Huang C, Zhao Q and Qiu Z: MicroRNA-301a-3p promotes pancreatic cancer progression via negative regulation of SMAD4. Oncotarget 6: 21046-21063, 2015.

20. Liu L, Nie J, Chen L, Dong G, Du X, Wu X, Tang Y and Han W: The oncogenic role of microRNA-130a/301a/454 in human colorectal cancer via targeting Smad4 expression. PLoS One 8: e55532, 2013

21. Hirata H, Ueno K, Shahryari V, Tanaka Y, Tabatabai ZL, Hinoda Y and Dahiya R: Oncogenic miRNA-182-5p targets Smad4 and RECK in human bladder cancer. PLoS One 7 : e51056, 2012

22. Qiao P, Li G, Bi W, Yang L, Yao L and Wu D: MicroRNA-34a inhibits epithelial mesenchymal transition in human cholangiocarcinoma by targeting Smad4 through transforming growth factor-beta/Smad pathway. BMC Cancer 15: 469, 2015.

23. Zhang Y, Fan KJ, Sun Q, Chen AZ, Shen WL, Zhao ZH,Zheng XF and Yang X: Functional screening for miRNAs targeting Smad4 identified miR-199a as a negative regulator of TGF- $\beta$ signalling pathway. Nucleic Acids Res 40: 9286-9297, 2012.

24. Zhao Y, Ji S, Wang J, Huang J and Zheng P: mRNA-Seq and microRNA-Seq whole-transcriptome analyses of rhesus monkey embryonic stem cell neural differentiation revealed the potential regulators of rosette neural stem cells. DNA Res 21: 541-554, 2014.
25. Geraldo MV, Yamashita AS and Kimura ET: MicroRNA miR-146b-5p regulates signal transduction of TGF- $\beta$ by repressing SMAD4 in thyroid cancer. Oncogene 31: 1910-1922, 2012.

26. Ying QL, Stavridis M, Griffiths D, Li M and Smith A: Conversion of embryonic stem cells into neuroectodermal precursors in adherent monoculture. Nat Biotechnol 21: 183-186, 2003.

27. Klincumhom N, Tharasanit T, Thongkittidilok C, Tiptanavattana N, Rungarunlert S, Dinnyés $\mathrm{A}$ and Techakumphu M: Selective TGF- $\beta 1 /$ ALK inhibitor improves neuronal differentiation of mouse embryonic stem cells. Neurosci Lett 578: 1-6, 2014.

28. Hwang M, Lee JM, Kim Y and Geum D: Functional role of parkin against oxidative stress in neural cells. Endocrinol Metab (Seoul) 29: 62-69, 2014.

29. Su H, Wang L, Huang W, Qin D, Cai J, Yao X, Feng C, Li Z, Wang Y, So KF, et al: Immediate expression of Cdh2 is essential for efficient neural differentiation of mouse induced pluripotent stem cells. Stem Cell Res (Amst) 10: 338-348, 2013.

30. Štefková K, Procházková J and Pacherník J: Alkaline phosphatase in stem cells. Stem Cells Int 2015: 628368, 2015.

31. Souquet B, Tourpin S, Messiaen S, Moison D, Habert R and Livera G: Nodal signaling regulates the entry into meiosis in fetal germ cells. Endocrinology 153: 2466-2473, 2012.

32. Guzman-Ayala M, Lee KL, Mavrakis KJ, Goggolidou P, Norris DP and Episkopou V: Graded Smad2/3 activation is converted directly into levels of target gene expression in embryonic stem cells. PLoS One 4: e4268, 2009.

33. Liu J, Wang L, Su Z, Wu W, Cai X, Li D, Hou J, Pei D and Pan G: A reciprocal antagonism between miR-376c and TGF- $\beta$ signaling regulates neural differentiation of human pluripotent stem cells. FASEB J 28: 4642-4656, 2014.

34. Du J, Wu Y, Ai Z, Shi X, Chen L and Guo Z: Mechanism of SB431542 in inhibiting mouse embryonic stem cell differentiation. Cell Signal 26: 2107-2116, 2014.

35. Tay YM, Tam WL, Ang YS, Gaughwin PM, Yang H, Wang W, Liu R, George J, Ng HH, Perera RJ, et al: MicroRNA-134 modulates the differentiation of mouse embryonic stem cells, where it causes post-transcriptional attenuation of Nanog and LRH1. Stem Cells 26: 17-29, 2008.

36. Boissart C, Nissan X, Giraud-Triboult K, Peschanski M and Benchoua A: miR-125 potentiates early neural specification of human embryonic stem cells. Development 139: 1247-1257, 2012.

37. Li Y, Wang F, Lee JA and Gao FB: MicroRNA-9a ensures the precise specification of sensory organ precursors in Drosophila. Genes Dev 20: 2793-2805, 2006

38. Yoon SO, Kim EK, Lee M, Jung WY, Lee H, Kang Y, Jang YJ, Hong SW, Choi SH and Yang WI: NOVA1 inhibition by miR-146b-5p in the remnant tissue microenvironment defines occult residual disease after gastric cancer removal. Oncotarget 7 : 2475-2495, 2016

39. Wang H, Jiang M, Xu Z, Huang H, Gong P, Zhu H and Ruan C: miR-146b-5p promotes VSMC proliferation and migration. Int J Clin Exp Pathol 8: 12901-12907, 2015.

40. Stevanato L and Sinden JD: The effects of microRNAs on human neural stem cell differentiation in two- and three-dimensional cultures. Stem Cell Res Ther 5: 49, 2014.

41. Avery S, Zafarana G, Gokhale PJ and Andrews PW: The role of SMAD4 in human embryonic stem cell self-renewal and stem cell fate. Stem Cells 28: 863-873, 2010.

42. Thomson M, Liu SJ, Zou LN, Smith Z, Meissner A and Ramanathan S: Pluripotency factors in embryonic stem cells regulate differentiation into germ layers. Cell 145: 875-889, 2011.

43. Ozair MZ, Noggle S, Warmflash A, Krzyspiak JE and Brivanlou AH: SMAD7 directly converts human embryonic stem cells to telencephalic fate by a default mechanism. Stem Cells 31: 35-47, 2013.

44. Ozair MZ, Kintner C and Brivanlou AH: Neural induction and early patterning in vertebrates. Wiley Interdiscip Rev Dev Biol 2: 479-498, 2013.

45. Sonntag KC, Simantov R, Björklund L, Cooper O, Pruszak J, Kowalke F, Gilmartin J, Ding J, Hu YP, Shen MM, et al: Context-dependent neuronal differentiation and germ layer induction of Smad4 $4^{-/}$and Cripto ${ }^{-/}$embryonic stem cells. Mol Cell Neurosci 28: 417-429, 2005.

46. Tropepe V, Hitoshi S, Sirard C, Mak TW, Rossant J and van der Kooy D: Direct neural fate specification from embryonic stem cells: a primitive mammalian neural stem cell stage acquired through a default mechanism. Neuron 30: 65-78, 2001.

47. Park KS: Tgf-Beta family signaling in embryonic stem cells. Int J Stem Cells 4: 18-23, 2011 